\title{
PEMANFAATAN KARET ALAM UNTUK PRODUK BARANG JADI DI DESA SUBAN JERIJI KECAMATAN RAMBANG DANGKU KABUPATEN MUARA ENIM
}

\author{
Abu Hasan ${ }^{1 *}$, Robert Junaidi $^{1)}$, dan K. A. Ridwan ${ }^{1)}$ \\ ${ }^{1}$ Jurusan Teknik Kimia Politeknik Negeri Sriwijaya \\ email: abu_hasan@polsri.ac.id; roju@polsri.ac.id; ka_ridwan@polsri.ac.id \\ ${ }^{*}$ Corresponding Author
}

\begin{abstract}
Besides the domestic consumption of natural rubber into rubber goods is still very small, Indonesia is also still dependent on the export of these commodities abroad. The new natural rubber producing countries which are quite troubling the world natural rubber market including Indonesia are also China, Vietnam and Cambodia. One of the main weaknesses of Indonesian farmers' natural rubber is dirty. This is a cause of low prices. The cost of cleaning the rubber is too high. Therefore it is indeed necessary to have a way to diversify rubber products or increase the consumption of natural rubber in the country is very important. In order for many people to produce rubber goods, this means that many people know that cleaning rubber is necessary and does not need to be polluted. In Palembang itself, there was PT. Sri Bina Havea and Intirub Tire Factory, but both are gone. Thus, the way to produce rubber goods of natural rubber needs to be socialized to the Indonesian people, especially in South Sumatetra. This certainly greatly influences the development of the local economy given that South Sumatetra is the largest producer of natural rubber in Indonesia and this result is mostly produced by farmers rather than large companies. For this reason, this service aims to provide information about the technology of processing natural rubber into rubber goods to the public. This service was carried out on the people of Suban Jeriji village, Rambang Dangku Sub-District, Muara Enim Regency, South Sumatra. The method used in this activity is a lecture and interactive discussion about the manufacture of natural rubber finished goods with the help of LCD and accompanied by providing samples of finished goods products from semi-finished natural rubber. The target to be achieved in this activity is the formation of insights into thinking that natural rubber goods are a way to overcome the ever-uncertain prices of natural rubber on the market. The long-term target of this activity is perhaps one day there are students or students who are interested in becoming entrepreneurs of natural rubber goods.
\end{abstract}

Keywords: natural rubber, rubber goods, Suban Jeriji, Rambang Dangku, Muara Enim

\section{PENDAHULUAN}

Desa Suban Jeriji yang terletak diantara hamparan hutan akasia milik PT. Musi Hutan Persada, Kecamatan Rambang Dangku, Kabupaten Muara Enim Provinsi Sumatera Selatan. Menurut sensus penduduk tahun 2017 yang baru lalu, terdapat sebanyak lebih kurang 3.867 jiwa. Penduduk desa ini terdiri dari penduduk asli dan para pendatang. Luas wilayahnya sekitar $5.473 \mathrm{~m}^{2}$. Sarana pendidikan yang tersedia meliputi satu PAUD, satu Taman Kanak-Kanak, satu SD Negeri, dan satu SMP Swasta.

Dilihat dari sarana pendidikan tersebut ternyata desa ini masih kekurangan sarana.
Untuk melanjutkan pendidikan ke jenjang yang lebih tinggi, mereka harus pergi ke desa lain dalam satu kecamatan. Mata pencaharian penduduknya adalah petani karet, buruh karet, buruh, karyawan swasta, PNS, dan lain-lain, namun yang terbanyak dari mereka adalah berprofesi sebagai petani karet pemilik lahan kebun. Sebagai gambaran ekonomi masyarakatnya terlihat dari harga karet yang kisarannya antara $\mathrm{Rp} 6.000$ - Rp 8.000 untuk setiap $\mathrm{kg}$. Harga ini tentu tidak dapat membeli beras yang harganya lebih tinggi dari karet. Harga karet di minggu terakhir 26 Januari 2018 sebesar Rp 7.700 setiap kg karet. 
Dari hasil diskusi antara tim pengabdi Jurusan Teknik Kimia Politeknik Negeri Sriwijaya dengan mahasiswanya yang berdomisili di desa Suban Jeriji, desa ini membutuhkan bimbingan bagaimana jalan keluar atau alternative untuk mengatasi harga jual petani karet yang selalu cenderung turun atau bahkan stagnant. Oleh karena itu disepakati sebagai tahap awal, dilakukan pengabdian dengan metode diskusi dan ceramah interaktif tentang teknologi karet untuk menghasilkan produksi barang jadi sebagai alternatif. Disamping itu untuk jangka panjang, masih dibahas dan didiskusikan tentang pembinaan teknologi karet di desa ini lebih jauh yang lebih nyata.

\section{IDENTIFIKASI MASALAH}

Masalah yang ada di bidang pasca panen karet alam adalah harga karet yang cenderung stagnan atau bahkan turun. Harga jual menjadi masalah utama bagi buruh sadap karet maupun petani pemilik lahan kebun. Ini tentu tidak mudah, di era persaingan produsen karet alam baru seperti dari Negara-negara Kamboja, Laos, Myanmar dan Vietnam yang telah memproduksi karet alam sekitar $13 \%$ global dengan tidak mengesampingkan produsen kawakan Negara Thailand dan Malaysia termasuk juga Indonesia sekitar $67 \%$ yang sudah lebih dahulu [1]. Barang jadi karet tentu suatu produk yang menjanjikan bahkan Indonesia pun menjadi konsumen barang jadi karet alam disamping sebagai eksportir karet alam mentah di dunia. Penduduk besar menjadi pasar yang besar pula bagi barang jadi karet alam.

\section{METODELOGI PELAKSANAAN}

Metode pelaksanaan pengabdian ini meliputi:

1. Presentasi dan diskusi interaktif dilakukan bagi para target yaitu masyarakat Desa Suban Jeriji dan perangkat desanya

2. Materi presentasi yaitu pengetahuan tentang karet alam, pengetahuan tentang uji rheometer (ISO 6502-1999) system vulkanisasi khususnya vulkanisasi belerang Morton, 1987 dan Bateman, 1963 untuk karet alam, bahan pengisi Blow dan
Hephurn, 1982 dan cara untuk menganalisis sifat fisik vulkanisat karet alam (ISO 34-1:2010; ISO 37-1994; ISO 816-1983; ISO 4649-1985;ISO 4662-2009 dan ISO 7619-1986) [2]-[11].

3. Menampilkan contoh barang jadi karet alam setengah jadi dan barang jadi karet melalui banner dan video.

4. Pretest dan post test dilakukan untuk mengetahui hasil yang dapat terserap oleh para peserta yang mengikuti presentasi diskusi interaktif

5. Memperlihatkan contoh karet alam setengah jadi dan bahan kimia karet serta bahan pengisi karet termasuk juga barang jadi karet kepada para peserta melalui video dan banner.

\section{HASIL DAN PEMBAHASAN}

Disini disampaikan hasil kegiatan pengabdian pada masyarakat tahun 2018

1) Peserta diskusi sangat tertarik dengan materi yang disampaikan selama sekitar 2 jam.

2) Peserta yang hadir sekitar 39 orang termasuk perangkat desa Suban Jeriji.

3) Materi ini merupakan ilmu baru bagi mereka sehingga untuk menigkatkan harga jual karet alam mereka tidak selalu tergantung hanya pada menjual karet mentah saja. Industry kecil perlu tumbuh untuk mendukung pemanfaatan karet alam yang harganya murah

4) Penyampaian transparan, banner, dan video teknologi karet yang terdiri atas pembuatan kompon karet, pengujian curing, dan pengujian sifat fisik. Pengujuan ini mengacu kepada standar uji nasional dan international.

5) Penyampaian contoh industry barang jadi karet yang kecil, menengah, dan industry besar. Misalnya industry pabrik ban kendaraan, industry vulkanisir ban bekas, dan pembuatan keset kaki serta serok karet untuk lantai melalui video. 
6) Terdapat banyak pertanyaan yang telah disampaikan dan telah dilakukan diskusi interaktif selama diskusi berlansung.

Berikut disampaikan foto-foto kegiatan sebagai gambaran suasana pengabdian pada masyarakat selama diskusi interaktif berlangsung di desa Suban Jeriji.

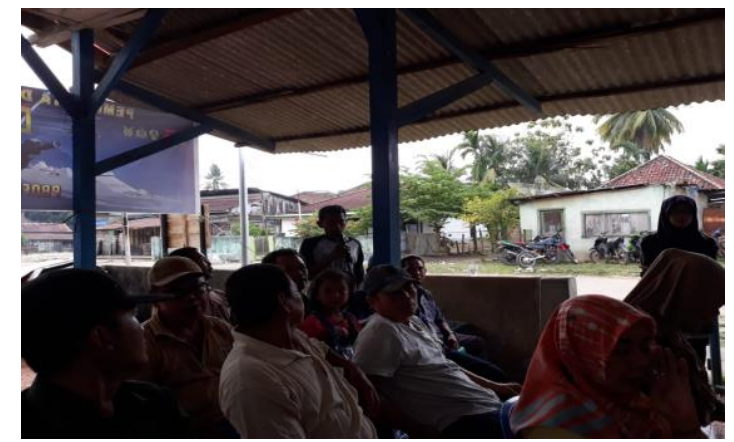

Peserta penyuluhan

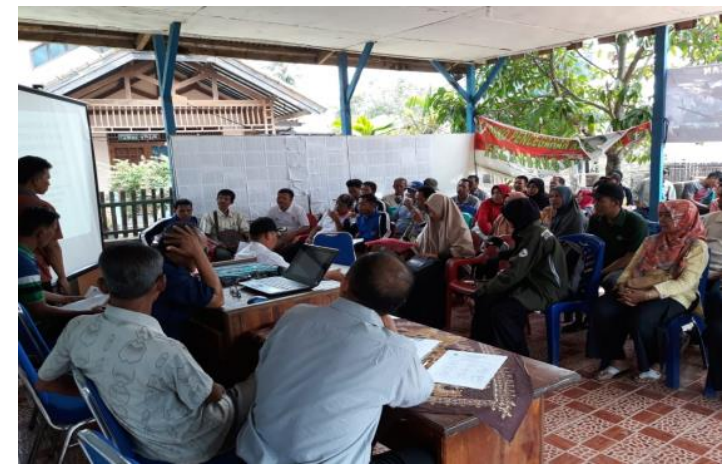

Penjelasan dan perkenalan dari Kepala Desa

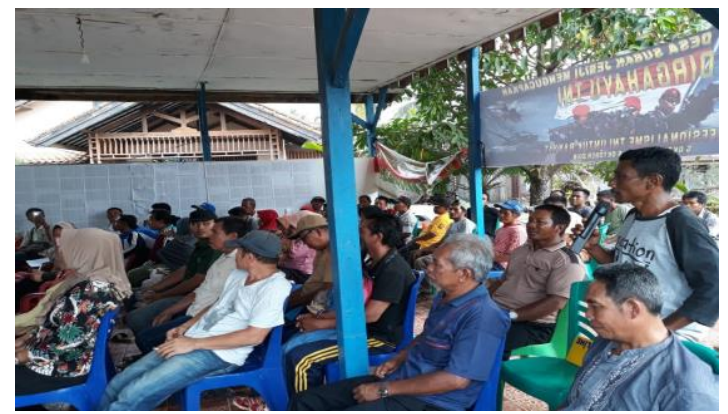

Peserta penyuluhan
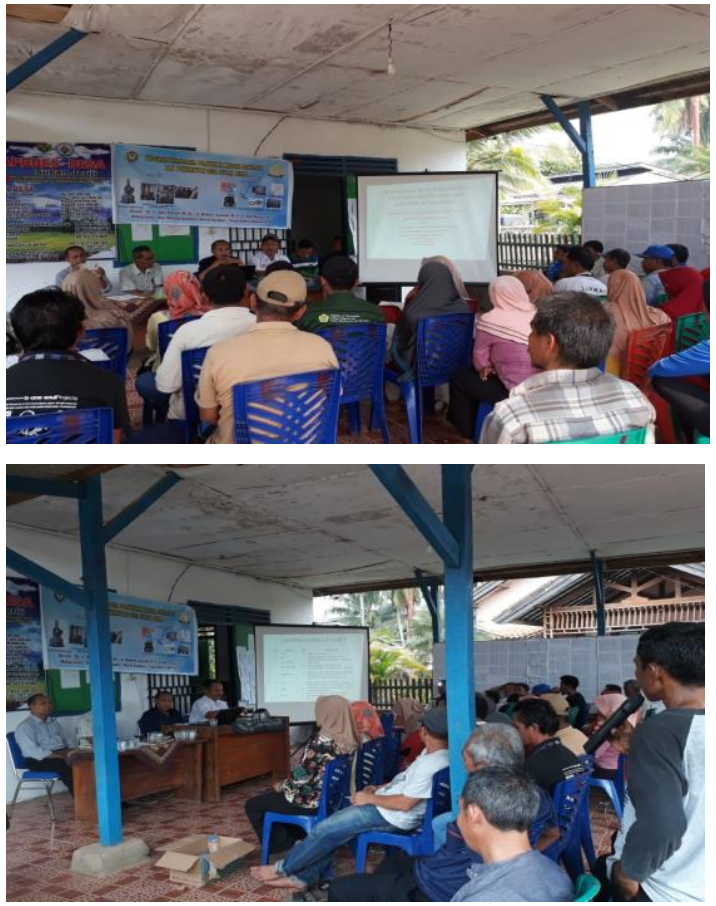

Penjelasan dari tim penyuluh

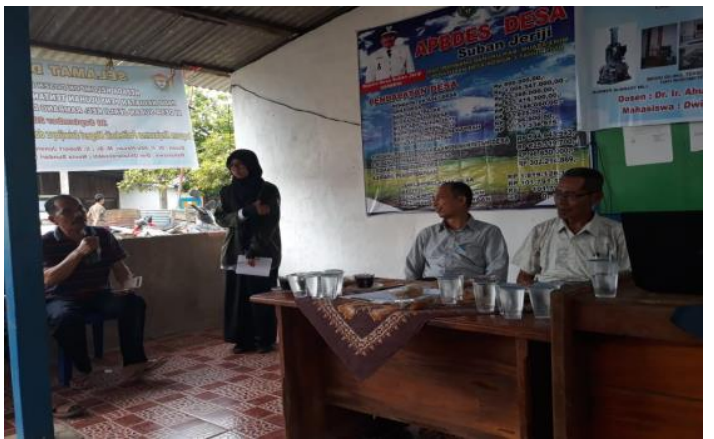

Salah satu peserta yang sedang mengajukan pertanyaan

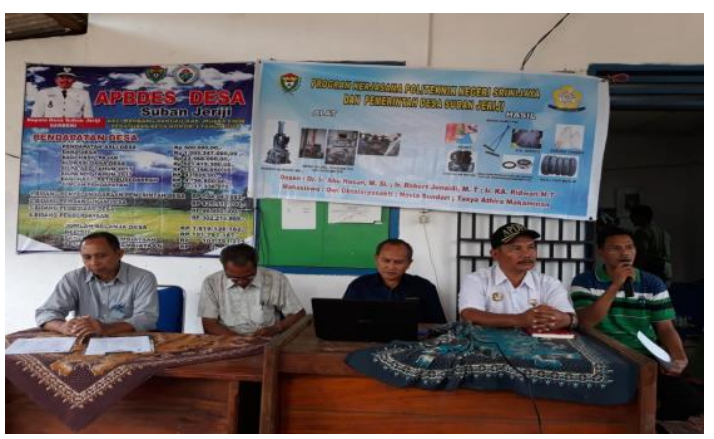

Tim penyuluh dan Kepala Desa 


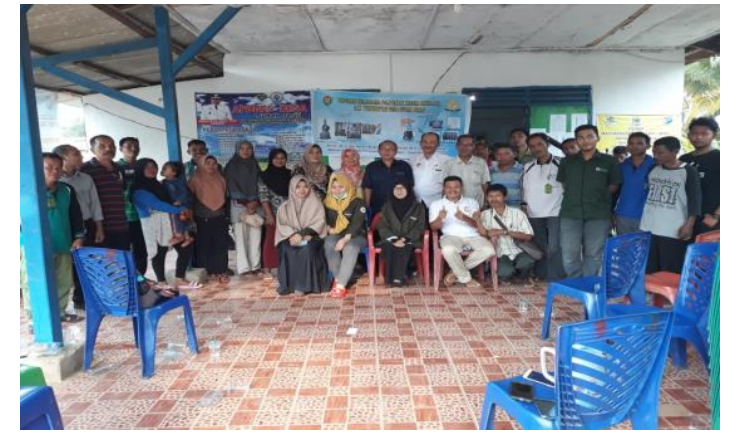

Foto bersama

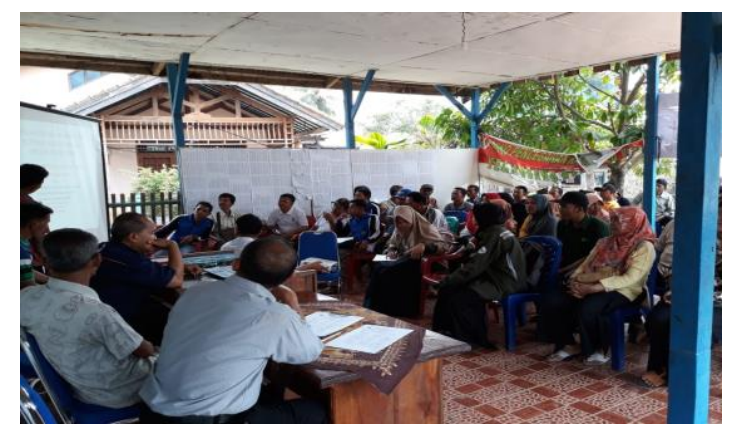

Suasana penyuluhan

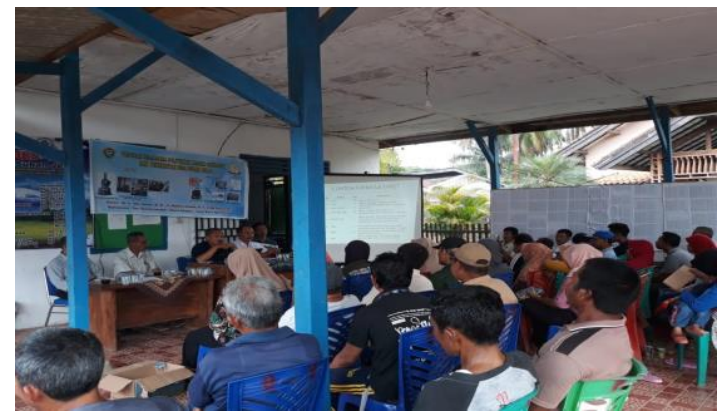

Suasana penyuluhan dan tanya jawab

\section{KESIMPULAN}

Kesimpulan yang diperolah dari pengabdian pada masyarakat ini adalah:

- Masyarakat Desa Suban Jeriji antusias memperhatikan ceramah dan diskusi yang berlangsung selama sekitar 2 jam. Mereka menganggap ini merupakan pengetahuan yang baru bagi mereka dan sebagai alternative untuk meningkatkan harga jual karet alam.

- Sebagian dari mereka yang hadir masih menginginkan peningkatan harga jual karet alam mereka tanpa memikirkan teknologi karet yang ditawarkan.

\section{UCAPAN TERIMA KASIH}

Ucapan terima kasih ditujukan kepada Politeknik Negeri Sriwijaya yang mendanai pengabdian ini khususnya pada P3M dengan nomor kontrak 3830/PL6.2.1/PM/2018 dan Kepala Desa Suban Jeriji dan warganya yang telah membantu pelaksanaan pengabdian ini.

\section{REFERENSI}

[1] Nurmayanti. (2014). Industri Karet Alam Kembali Sumringah Tahun Depan. Jakarta: Liputan 6.

[2] Rubber, Determination of indentation hardness by means of pocket hardness meters. (1986). ISO 7619 . ISO.

[3] Bateman, L. (1963). The Chemistry and Physics of Rubberlike Substances: Study of the Natural Rubber Producers' Research Association . London: MacLaren\&Sons ltd.

[4] Blow C. M. and Hephurn, C. (1982). Rubber Technoogy and manufacture. London: 2 nd Butterworth Csientifis.

[5] Morton, M. (1987). Rubber Technology. New York: Van Nostrand Reinhold.

[6] Rubber, Determination of abrasion resistance using a rotating cylindrical drum device. (1985). ISO 4649 . ISO.

[7] Rubber, Guide to the use of curemeters. (1999). ISO 6502 . ISO.

[8] Rubber, vulcanized or thermoplasticDetermination of rebound resilience. (2009). ISO 4662 . ISO.

[9] Rubber, vulcanized or thermoplasticDetermination of tear strength-Part1: Trouser, angle and crescent test pieces. (2010). ISO 34-1 . ISO.

[10] Rubber, vulcanized or thermoplasticDetermination of tensile stress-strain properties. (1994). ISO 37 . ISO.

[11] Rubber, vulcanized-Determination of tear strength of small test pieces (Delft test pieces). (1983). ISO 816 . ISO. 